Original Article

\title{
A DESCRIPTIVE STUDY TO ASSESS THE KNOWLEDGE ON BREAST CANCER AND UTILIZATION OF MAMMOGRAM AMONG WOMEN IN SELECTED VILLAGES OF UDUPI DISTRICT, KARNATAKA
}

\author{
Arkierupaia Shadap ${ }^{1}$, Maria Pais ${ }^{2} \&$ Anusuya Prabhu ${ }^{3}$ \\ ${ }^{1}$ Lecturer, Sikkim Manipal College of Nursing, Sikkim Manipal University, \\ Sikkim - 737 102, ${ }^{2,3}$ Assistant Professors, Manipal College of Nursing, Manipal University, Manipal, Karnataka - 576104. \\ Correspondence : \\ Arkierupaia Shadap \\ Lecturer, Sikkim Manipal College of Nursing, Sikkim Manipal University, Gangtok, Sikkim - 737102. \\ Mobile : +91 8116213637 E-mail : arkie_ro@rediffmail.com
}

Abstract :

Breast cancer was considered to be one amongst the most commonly cancer disease in the world. Now it is considered to be the second cancer disease among women in India, with most of the affected population is in the urban areas. Breast cancer is seen mostly after the age of 40 years. According to the Cancer fact 2012, breast cancer is now seen to be among women aged from 35 years above.

Materials and methods : The study was a descriptive survey study to assess the knowledge on breast cancer, awareness and utilization of mammogram among 320 married and unmarried women who were willing to participate in the study. After the consent, a questionnaire prepared by the investigator was given to them.

Results: Majority $46.6 \%$ had low knowledge for breast cancer. There was an association between knowledge and age, marital status, education and source of information about breast cancer and it was found to be significant $(p<0.05)$. Mammogram is underutilized among participants, from the total number of population i.e; $n=320$, only $19.1 \%$ (61) were aware of mammogram. Out of 19.1\% (61) who were aware of mammogram, did not utilise it.

Conclusion: The study concluded that women have low knowledge on breast cancer and very less population was aware of mammogram which is one of the screening tests for breast cancer. Their low knowledge on breast cancer and unaware of the screening test is the main reason for not utilising mammogram even those who are aware of it. So, nurses as health care members play an important role in providing information and educating the community people.

Key words: Knowledge, breast cancer, utilization, mammogram.

\section{Introduction :}

Breast development occurs in distinct stages throughout a woman's life from birth to puberty, during menstruation period, child bearing age and till woman reaches menopause. Once ovulation and menstruation begin, the maturing of the breasts begins and continues to grow. Women may also experience changes in breast texture and feeling particularly lumpy. As age increases by 35 years,

\begin{tabular}{|c|}
\hline Access this article online \\
\hline Quick Response Code \\
\hline
\end{tabular}
there is a gradual shrinking of the mammary glands. By the time a woman reaches her late 40 s and early 50s, menopause begins and the levels of o e s trog e $n$ a $n d$ progesterone begin to fluctuate, with levels of oestrogen dramatically decreasing and this leads to many symptoms. The connective tissue of the breast becomes dehydrated and inelastic, and the breast tissue shrinks, loses shape and leads to the "sagging" of the breasts. As age advanced these are the changes in woman's breast which are normal, but some woman may have changes like lump which are tender and non-tender, abnormal discharge from the breast, ulceration, redness; these are all the early pathological changes which may cause malignancy.

Globally more than one million women are estimated to be diagnosed with breast cancer every year, and more than 410,000 will die from breast cancer. Cancer facts revealed that the age-standardised incidence rate for breast cancer in India is 22.9 per 100,000 , one-third that of Western 
countries and the mortality rates are disproportionately higher. Breast cancer accounts for $22.2 \%$ of all new cancer diagnoses and $17.2 \%$ of all cancer deaths among women in India. Breast cancer in urban areas of India is three times higher than in rural parts of the country.

According to India statistics, the number of new breast cancer cases is about 115,000 per year and this is expected to rise to 250,000 new cases per year by 2015 . If discovered early breast cancer can usually be cured; however, early detection through screening is the only way to reduce mortality. The most common screening for the early detection is breast self-examination and mammogram. It has been shown that it reduced the breast cancer mortality by $30 \%$ in women aged 50 and older. A descriptive study done at Saudi, found that $56 \%$ women were unaware of these changes and some of them are reluctant to go for check-up due to many reasons such as; lack of knowledge, shyness, fears and delay in the treatment leads to complications and death. Breast cancer has overtaken cervical cancer to become the leading site of cancer in Delhi, Bangalore, Mumbai, Chennai, Bhopal, Ahmedabad, Kolkota with the relative population ranging from $21.7 \%$ 28.7\%. Incidence of breast cancer in Bangalore increased from $14.5 \%$ in 1990 to $23.5 \%$ in 2005 . Cases of breast cancer among younger age group have increased by 15 $20 \%$. It indicates each year, 1,82000 women are diagnosed with breast cancer and 43,300 die. It has been observed that breast cancer has been increasing in its onset in the Karnataka with $25 \%$ of the cancer is breast cancer.

Promotion of health and prevention of disease is a very important responsibility of nurses towards the community people. There is no doubt that nurses are effective health care workers in disseminating the knowledge on breast cancer, its screening tests and motivate the utilization of health care services. Also facts gathered from literatures revealed that there is less study related to breast cancer and utilization of mammogram among the community people of Udupi. So, in an attempt to elicit the knowledge and utilization of mammogram as a screening tool for early detection, "a descriptive study to assess the knowledge on breast cancer, awareness and utilization of mammogram among women in the selected villages of Udupi" was undertaken.

The purpose of undertaken the study was to provide information through health education and leaflet on breast cancer based on their knowledge on breast cancer, awareness and utilization of mammogram. This provides the evidence base regarding the importance of health information for preventing morbidity and mortality among the target populations.

\section{Materials and Methods:}

The research design selected for the study was a descriptive survey approach. A non-probability purposive sampling technique was used to select the sample for the study. The sample consists of three hundred and twenty women residing at Arthrady and Hirrebettu villages, Udupi District, Karnataka. Three tools were developed and send for pretesting after content validity and test-re-test reliability. After the ethical clearance, administrative permission and consent from participants, data was collected using the following tools during $15^{\text {th }}$ Jan. 2013 to $22^{\text {th }}$ Feb. 2013.

1. Tool 1: Demographic proforma

2. Tool 2: Knowledge questionnaire on breast cancer

3. Tool 3: Utilization of mammogram

\section{Findings of the study:}

The study findings revealed that $42.1 \%$ of the women were within the age group of $35-44$ years. About $85.9 \%$ are married women and $92.5 \%$ belonged to the Hindu religion. Majority $45.3 \%$ had primary education, occupation of these women $59.4 \%$ were housewife and $59.4 \%$ of their monthly family income falls within Rs.3001-5000. Out of 320 women, $87.5 \%$ have heard about breast cancer and $42.8 \%$ obtained the source of information from the health personnel. (Table 1$)$ 
Table 1: Frequency and percentage distribution of sample characteristics

$\mathrm{N}=320$

\begin{tabular}{|c|c|c|c|}
\hline & & Frequenc & entage (\%) \\
\hline 1. & Age(years) & & \\
\hline & $35-44$ & 135 & 42.1 \\
\hline & $45-54$ & 114 & 35.6 \\
\hline & 55 and above & 71 & 22.2 \\
\hline 2. & Marital status & & \\
\hline & Married & 275 & 85.9 \\
\hline & Unmarried & 24 & 7.5 \\
\hline & Separated/Widow & 21 & 6.6 \\
\hline 3. & Religion & & \\
\hline & Hindu & 296 & 92.5 \\
\hline & Muslim & 24 & 7.5 \\
\hline 4. & Education & & \\
\hline & Primary & 145 & 45.3 \\
\hline & High school & 94 & 29.4 \\
\hline & Higher Secondary & 37 & 11.6 \\
\hline & PUC/ Graduate/PG & 44 & 13.8 \\
\hline 5. & Occupation & & \\
\hline & Government/Private employee & 43 & 13.4 \\
\hline & Self-employee & 53 & 16.6 \\
\hline & Daily wage & 34 & 10.6 \\
\hline & Housewife & 190 & 59.4 \\
\hline 6. & Family monthly income in rupee & & \\
\hline & $\leqslant 3000$ & 69 & 21.6 \\
\hline & $3001-5000$ & 190 & 59.4 \\
\hline & $\geqslant 5001$ & 61 & 19.0 \\
\hline 7. & Heard about breast cancer & & \\
\hline & Yes & 280 & 87.5 \\
\hline & No & 40 & 12.5 \\
\hline 8. & Source of information & & \\
\hline & Friends & 24 & 7.5 \\
\hline & Relatives & 46 & 14.4 \\
\hline & Health personnel & 137 & 42.8 \\
\hline & Mass media /Newspapers & 73 & 22.8 \\
\hline
\end{tabular}

Figure 1: Pie diagram showing percentage of knowledge score on breast cancer among women $\quad \mathrm{N}=320$

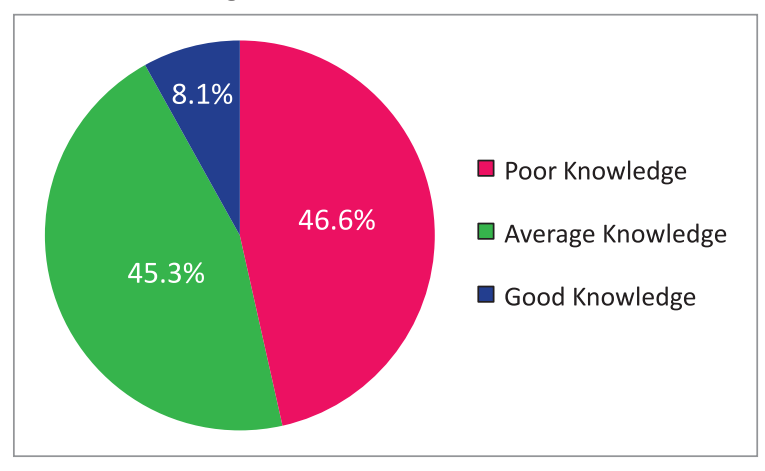

Figure 2: Bar diagram showing percentage of awareness of mammogram among women $\mathrm{N}=320$

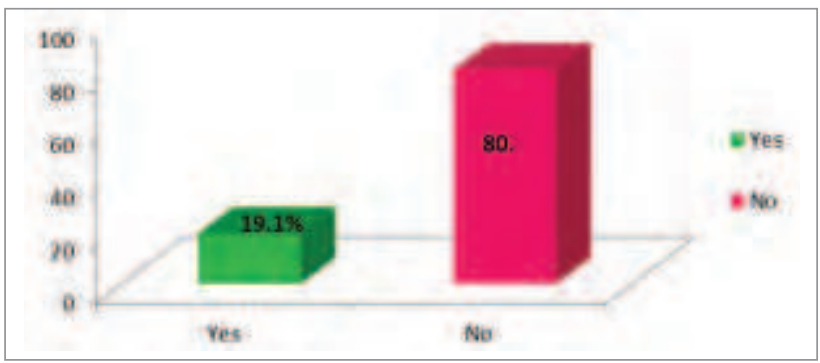

Figure 3: Cone diagram shows women (19.1\%) who were aware of mammogram

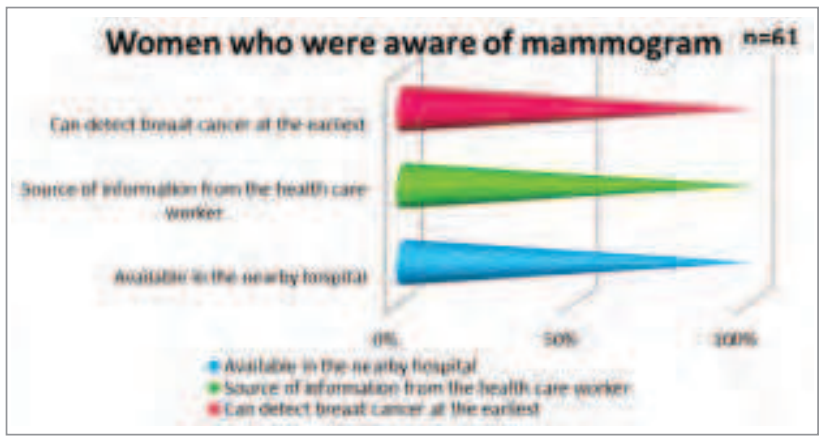

Out of 320 women, $46.6 \%$ had poor knowledge, $45.3 \%$ had average knowledge and $8.1 \%$ had good knowledge score on breast cancer. (Figure 1)

Out of 320 women, majority $80.9 \%$ are not aware of mammogram and only $19.1 \%$ are aware of it and none had utilized mammogram.(Figure 2)

Of $61(19.1 \%)$ women who were aware of mammogram, $49.1 \%$ know that it is available in nearby hospital. The sources of information for the mammogram are majority $67.2 \%$ from health personnel and $72.1 \%$ believe that mammogram can detect breast cancer at the earliest.(Figure 3)

Knowledge on breast cancer was found to be significantly associated with variables like age, marital status, education and source of information about breast cancer. Chi square test was used to find the association between knowledge and the demographic variables.

The limitations of the study were, since non-probability sampling and only two villages were used, so generalization of the study was limited to the sample. Association of the utilization of mammogram cannot be 
done, as none of the sample has undergone mammogram utilization.

Implications: The study revealed that women were having low knowledge on breast cancer and very less population were aware of mammogram which is one of the screening test for breast cancer. Their low knowledge on breast cancer and unaware of the screening test is the reason for not utilising mammogram even those who are aware of mammogram. There was a significant association of knowledge on breast cancer to age, marital, education and source of information about breast cancer. These findings have the wider implications for nursing practice, education, administrator and research.

A nurse educator may be oriented through the findings of the present study and able to provide adequate education and assist the people in developing their self-care potential. Nurses are the important and responsible providers who play an important role in imparting knowledge and help the community people in the early detection of the breast cancer. The present nursing curriculum is community oriented where emphasis is given to preventive aspects rather than curative. The practice nurse can encourage and motivate the target population for health seeking behaviour. Innovative teaching can be used for imparting the knowledge to the public which in turn will improve their utilization of the available health

\section{References:}

1. Tarek Amin, Mulhim Al, Abdullah Meqihwi. Breast cancer knowledge, risk factors and screening among adult Saudi women in a primary health care setting. Asian Pacific Journal of Cancer Prevention.2009; $10: 133-138$

2. Karayurt O, Ozmen D, Cetinkaya A. Awareness of breast cancer risk factors and practice of breast self-examination among high schoo students in Turkey. BMC Public Health 2008; 8: 359- 62.

3. TS. Tang, LJ. Solomon, McCracken. Cultural barriers to mammography, clinical breast exam, and breast self-exam among Chinese-American women 60 and older. Preventive Medicine. 2000 Nov; 31(5): 575 - 83

4. American Cancer Society. Cancer Facts and Figures 2005. http://www.cancer.org

5. http:// www. The hindu.com/todays- paper/ tp-national/ tpKarnataka/article 3701640.ece.

6. http://www.hopkinsmedicine.org/healthlibrary/conditions/adult/br east_health/normal_breast_development_and_changes_85,P0015/

7. Ahuja. S, Chakrabarti. N. To Determine The Level Of Knowledge Regarding Breast Cancer And To Increase Awareness About Breast Cancer Screening Practices Among A Group Of Women In A Tertiary Care Hospital In Mumbai, India. The Internet Journal of Public Health. 2010.1(1). DOI: $10.5580 / 1 b 7 c$ care services. As a nurse administrator we can organize awareness programme and proper education for the community women regarding breast cancer and how to identify the risk factors for the early detection and prevention of morbidity and mortality rate. Data will provide the new concept to conduct further research in the field of nursing practice. This will further improve the community women's health and motivate them to adopt healthier lifestyle.

\section{Conclusion:}

To conclude, we can make more recommendations. Indepth health education messages through mass media, newspapers should be tailored to fulfill knowledge gap among all population. Intensive educational campaigns to tackle the observed educational deficits should be planned in order to raise awareness towards breast cancer its risk factors with emphasis on role of prevention and guidelines for screening through self -breast examination, clinical breast examination and mammography. We as nurse must continue to remind and update the community women about breast cancer disease and women's cancer screening practices must be reinforced.

\section{Acknowledgement :}

We would like to thank all the participants and friends for their contribution and support during the study. 